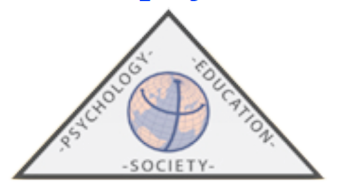

\title{
An Australian Perspective on Teacher Professional Development in Supercomplex Times
}

\author{
Lorraine M. LING* \& Noella M. MACKENZIE** \\ (*) La Trobe University, (**) Charles Sturt University (Australia) \\ (Received on February 20, 2015; Accepted on July 27, 2015)
}

\begin{abstract}
Professional Development is one of many terms given to the in-service education and training of teachers. In this paper, the authors address the kinds of professional development currently offered in Australia and compare it with the kinds of professional development teachers may require to deal with an era of supercomplexity, where there is uncertainty, insecurity and an unknown and unknowable future. Professional development is seen as involving multiple stakeholders and the influence of governments and other external bodies is also critically examined.
\end{abstract}

Keywords: teachers, professional learning, learning outcomes, unknown futures, uncertainty

Correspondence: Emeritus Professor Lorraine M. Ling. La Trobe University. Bundoora 3086. Victoria, Australia. Email: L.Ling@1atrobe.edu.au

How to cite this article?

Ling, L. M., \& Mackenzie, N. M. (2015). An Australian perspective on teacher professional development in supercomplex times. Psychology, Society and Education, 7(3), 264-278. 


\section{Introduction: Unknown Futures}

Education for the 21st century is complicated by our unknown future (Barnett, 2012). In claiming that the future is unknown we refer to a situation where knowledge is always revisable and provisional, where the kinds of skills required for the future are unknown given that the kinds of contexts in which we will live and work are largely unknown. To some extent, the future is always unknown. However, in an era of supercomplexity, this is compounded by the fact that the frameworks and rules by which we have evaluated the current context and the potential future context are themselves constantly shifting and changing. While some may claim that the future has always been unknown, in contemporary times it provides "a new pedagogical challenge if not urgency" (Barnett, 2012, p. 65). The impact of unknown futures on teaching and learning is significant and redefines the way teachers and learners conceive of knowledge and skills especially.

The Professional Development (PD) needed to prepare teachers to guide students towards an unknown future is required to present a range of concepts and ideas, leading teachers into new ways to approach their own work as experimenters, explorers, innovators, and risk takers. Many of the current PD programs in Australia, especially those that are designed to train teachers in particular programs or to use particular published materials, are dogmatic and prescriptive and allow little or no room for the teacher to interact creatively with the curriculum or with pedagogical approaches. Such programs are unlikely to prepare teachers or learners to face the unknown. An unknown future requires us to take an 'ontological turn' (Barnett, 2012, p. 65) whereby we are impelled to rethink what it is to be a teacher and to be a learner, as these identities are shifting as our old frames of reference shift. PD programs can potentially lead to and facilitate such rethinking as is discussed here.

\section{PD in Australia Now: What Does it Look Like?}

PD is given many names and acronyms: Professional Learning (PL), Continuous Professional Development (CPD), In-service Education (ISE) and Work Place Training (WPT) are just a few. Teacher PD usually refers to learning opportunities provided to practicing teachers and teacher educators. In many cases, PD is initiated and provided by employers, although in the current Australian context it is often provided by professional associations, publishers and private consultants, with universities entering more seriously into this arena in the past two decades or so. Increasingly, PD in Australia is offered via webinars or on-line workshops and short courses.

By way of background we note here that initial teacher education in Australia is of four years minimum duration and can take the form of an undergraduate degree following on from Year 12 of schooling, or can be a graduate entry course of two years duration, following a basic discipline-based degree generally of three or four years duration. We as teacher educators in Australia, are at pains to emphasise the fact that pre-service teacher education cannot and should not be expected to produce teachers who are experts, ready and able to deal immediately with all of the complexities of teaching. It takes time, experience and ongoing learning. Thus 
continuing PD for teachers throughout their career is critical, and is an expectation and often a requirement, as it is within any profession. In this paper we will refer to "educational workplaces" to encompass all possible teaching locations, for example schools, early childhood centres, colleges and universities.

The Australian Institute for Teaching and School Leadership (AITSL), which is the overarching regulatory and accrediting body for teacher education programs in Australia, undertook a study in 2011 to inform a national PD framework for teachers and school leaders in Australia. In that study, four broad principles for quality effective professional learning were identified. These were:

1. the need to make professional learning core school business;

2. the need for PD to focus on outcomes for students;

3. the need for the development of deep pedagogical content and assessment knowledge when the outcomes focus on academic areas; and

4. the need to construct professional learning environments that are consistent with the ways people learn.

PD for teachers as well as for teacher educators in Australia takes many paths which include half day and day workshops, modules of 12 to 15 hours of PD (in some cases creditable to a formal university qualification, undertaking full award courses such as Masters and Doctoral degrees), mentoring and coaching, action research projects and many other variations on these themes. Much PD in Australia is still provided in a format that involves a one-way transmission of knowledge between the sender (PD provider) and the receiver (the teacher undertaking the PD program). Such programs allow little creative input from the teachers involved and thus this is more about PD done "to" teachers than about PD conducted "by" or "with" teachers. In this common version of PD, three elements (the PD provider; the teacher; and the educational workplace) often operate quite independently of one another. This PD approach may lead to an increase in a teacher's information or knowledge, but rarely leads to any real change in practice, and in many cases there is little if any transfer of knowledge or practice from the PD participant to their colleagues.

Despite these criticisms, this approach can however ignite a spark that may, if followed up quickly, lead to further exploration of a topic, approach or concept. If a group of people from a particular educational workplace attends PD sessions given in this way they can sometimes work together and continue to explore their learning on return to their school. However, with the pressure of work and without the encouragement of educational leaders to do so, often after a week or so, the PD participants' practice shows no evidence of their participation in the PD, even if they have gained in terms of knowledge. What tends to be missing from this approach is opportunity for dynamic interaction between the PD providers, the participants and the schools.

A more dynamic approach to PD is one where the three main elements - PD provider, participants and educational workplaces - are involved in negotiation and collaborative design of a PD program which satisfies an identified need or specific objective. Through dynamic interaction of the three key players in the PD activity, all 
parties are actively involved at all stages of the PD process. The expectation with this approach is that there is room for ongoing change and adaptation to the PD activities throughout the process, as a result of the interaction between the three key stakeholders as outlined above. Both the one-way, didactic approach and the second more interactive and dynamic approach to PD are evident in the Australian context at this time.

\section{How Much PD is Enough?}

In terms of the frequency of PD for participants in Australia currently, while most states in Australia now specify a minimum number of hours of PD which teachers must undertake in a given time period, in some instances, this is a recent policy. Unlike other legislative bodies governing other professions, education departments and accrediting bodies in Australia have not in the past mandated PD with any consistency or in a particularly robust manner. Cole (2012) argues that mandating PD "tends to reinforce the often false perception that there is a strong link between professional learning and improved teaching practice and whole school improvement" (p.5).

There is also a possibility that mandating PD can lead to teachers "ticking off" their required hours in the most perfunctory manner possible so that they are able to retain their registration. Nevertheless, since November 2008, Victorian teachers have been required to declare that they have undertaken a "defined quantity and scope of professional development activities when applying for renewal of registration" (FAQs, vit.vic.edu.au). That "defined quantity and scope" translates to at least 20 hours of PD that is referenced to the Australian Professional Standards for teachers each year. The VIT documentation states that "Professional development activities should update knowledge about pedagogy, content and/or practice" (FAQs, vit.vic.edu.au). Other states and territories have similar requirements. However, many teachers exceed the 20 hours required to qualify for renewal of registration especially as the categories and types of PD involve both formal and informal activities and are broad in scope.

A study commissioned by the Australian Department of Education, Employment and Workplace Relations (DEEWR, 2011), however, found that Australian primary school teachers as a whole had engaged in an average of 9 PD days (both formally and informally organised activities) in the past year whilst secondary teachers engaged in 7.6 days. More than half of the teachers who engaged in PD activities were specialist teachers in the area of literacy, numeracy and special needs with the highest proportion of participation in literacy. The lowest participation in specialist areas in PD was in computing teaching. For secondary teachers in seven of the specialist areas surveyed (Biology, Physics, Chemistry, General Science, Geography, History, and Computing) less than half of the participating teachers had engaged in any recognised PD. The highest levels of PD participation in the secondary teachers surveyed were in English and Languages Other Than English (LOTE). 
However, an increased quantity of PD does not necessarily mean that it is effective. Underpinning any discussion of PD will be a key concern for what constitutes effective PD, and currently in Australia this forms the focus of considerable research.

\section{What is PD effectiveness and how is it measured?}

Almost 20 years ago, Mackenzie (1997) contended that PD should only be deemed effective if it led to change in practice, and by extension, improved outcomes for students. Mackenzie argued however that, at that time, most PD appeared to lead to changes in teachers' knowledge and awareness but not to changes in practice. In the later study conducted by the Department of Education, Employment and Workplace Relations (DEEWR, 2011) in Australia, it was reported that the majority of teachers surveyed described the PD they undertook as being valuable in terms of their own knowledge and skill development, suggesting that 'knowledge transfer' is still the focus of much teacher PD. While teachers surveyed by DEEWR in 2011 claimed that PD had increased their effectiveness in promoting student learning to either a major or a moderate extent, the evidence was based on self-reports. Teachers reported that specific areas in which they most needed PD were: methods to assess student learning; methods of engaging students in subject matter; content knowledge; development of relevant learning materials; planning learning goals for students; and broadening the range of subjects they are able to teach (DEEWR, 2011).

These areas identified by teachers as needing to be a focus for PD point to a perceived need for teachers to actively learn new skills and teaching strategies. It is suggested here that teacher professional learning (PL) must take centre stage if change in practice and improved student outcomes are to be the desired outcome of PD. Teacher learning, according to Ofter and Pedder (2011), must focus on the reciprocal interaction of the teacher, the school and the learning activity in which the teacher is engaged. This is consistent with a study conducted by Cole (2012) which concluded that in the Australian context, effective PD needs to be "embedded in or directly related to the work of teaching, grounded in the content of teaching, organised around collaborative problem solving, and integrated into a comprehensive change process" (p.7). Both study findings align with the dynamic and interactive approach we outlined earlier, where all of the stakeholders - the PD provider, the participants and the educational workplace - are reciprocally and interactively or dynamically involved in all stages of the PD program.

With regard to the time taken between teachers undertaking PD activities and there being observable change in their practice, Cole (2012) found that the time-lag:

[...] between when professional learning occurs, teacher practice changes and student learning improves, and the multiplicity of influences on a teacher that could contribute to changes in their practice, makes research into "best practice" professional learning fairly problematic at this stage (p.8).

Cole (2012) suggests that the most effective teacher PD in terms of changing teacher practice and improving student outcomes relies on PD being a routine 
practice in the school and involves teaching "experts" working with teachers in their classrooms or through teachers working together and learning from each other. Cole also found that effective PD:

1. focuses on teaching strategies and the mastery of teaching techniques and involves micro-teaching strategies and techniques;

2. is a whole school endeavour designed to produce better teaching practice based on evidence;

3. involves teachers developing individual professional learning plans and making these public so that other teachers with the same focus of PD as theirs, could support each other and work together. These need to be regularly reviewed and renewed each new teaching term.

A number of key factors tend to mitigate against effective PD and these centre mainly around:

1. teacher reluctance to mentor or coach colleagues;

2. teacher reluctance to ask for support or assistance from colleagues;

3. lack of time to participate in PD activities; and

4. a refusal to admit to the importance of PD and collegial support (Cole, 2012).

What is needed, according to Cole (2012), is a culture of Professional Learning to be established in all schools with teachers assuming responsibility for this culture. Such a culture would facilitate highly experienced teachers to formally coach and mentor their less experienced colleagues. A final and telling finding in this Australian study is that:

In a school context where teachers are not collaborative and used to sharing ideas and experimenting with their teaching practice, even professional learning programs with solid content and powerful training strategies, are unlikely to be effective (Cole, 2012, p.14).

In another Australian study, Ingvarson, Meiers and Beavis (2005) reviewed four PD programs specifically designed to enhance teacher quality. They surveyed participating teachers at least three months after participation in the PD activities. From the study they identified five main characteristics of effective PD: content focus, follow up, active learning, feedback, and collaborative examination of student work. Impact was measured in terms of teacher knowledge, practice, student learning outcomes, and teacher efficacy, although data relied on teacher self-report surveys. There was no discussion of change in practice.

Cole (2012), in the Australian study of PD, claims that previous surveys such as those undertaken in Australia by Corcoran (1995), Ingvarson (2003) and Supvitz and Turner (2000):

[...] reveal that professional learning generally consists of unfocused, fragmented, low-intensity activities, such as short-term workshops with little or no follow-up and consequently that the capacity of the profession to engage 
most of its members in effective modes of professional learning over the long term has been weak (p.5).

This finding is disappointing as an answer to the question of what constitutes PD efficacy, and is part of the challenge we face to bring PD into a new era, thus leading to the question of what is needed for a change in practice and for improved student outcomes to result from teacher PD in the current era? In an era of supercomplexity where the future is unknown and uncertain, and where there are competing values, pressures and agendas which teachers will need to face and deal with, PD will be required to facilitate and strengthen certain key skills and attributes in teachers which prepare them for teaching in this era. PD will need to involve a significant element of critical reflection and potential for unlearning, changing and relearning teaching skills and approaches that are no longer working or appropriate. PD will need to encourage teachers to confront and question their own understanding of what it is to be a teacher and also to challenge their own understandings of what learners require to prepare them for the present and future. The kind of teacher critical reflection that this requires is more likely to be of a kind which actively involves PD providers, teachers and the schools in dynamic interaction. PD of the embedded type, which Cole (2012) has outlined, is also likely to be effective especially when it involves school-based mentors working in classrooms beside and with teachers in a routine and ongoing manner. This approach also reflects the dynamic interactive model of PD rather than the one-way didactic transmission model.

\section{PD for Supercomplexity}

In an era of supercomplexity, any PD which focuses on skills and knowledge can really only be useful for the past or, at best, the immediate present, as we do not know precisely what skills will be most required in the unknown workplace of the future. Rather, we need PD which focuses on the development of "human qualities and dispositions" (Barnett, 2012, p.65). This implies that teachers will need to look reflectively and radically at the whole being and essence of teaching and learning and indeed of schools and their purposes. This will necessitate a change in the way we conceptualise learning and the meanings we attribute to it. We will also need to rethink the very being of learning and what it means to be a learner in the current era and into the future. PD will need to assist teachers to develop dispositions and attributes which equip them to live with uncertainty, constant change, multiple and often conflicting values and demands, and to accept that their own knowledge is provisional and always open to reinterpretation and question against different and shifting frames of reference.

This confronts the "sage on the stage" mentality and favours the "guide on the side" or the co-learner role for teachers where students and teacher have a joint role to play in the creation of meanings and of knowledge at any given moment. In a supercomplex world, teachers across all sectors of education will need to introduce "strangeness" into their own and their students' experiences (Barnett, 2015). By this 
Barnett means that, as human beings, we will need to be comfortable with awkward situations and with not knowing the future and also with knowledge being provisional at best, thus we need to be comfortable taking risks and accepting change and insecurity as the norm rather than something to be resolved or fixed. In light of this notion, Barnett (2015) regards teaching for an unknown future as:

[...] the production of human capacities, qualities and dispositions - for the personal assimilation and creation of strangeness. Such a conception of teaching looks to a fundamental break with conventional pedagogical relationships and looks to curricula that present awkward spaces to and for the students. Through such spaces, the learner will realize for themselves their capacities for assimilating and even producing strangeness (p.94).

This fundamental break with conventional pedagogical relationships will also need to be reflected in the pedagogy of PD. The type of pedagogy required in supercomplexity will need to be eminently open and flexible, to assist teachers to be adaptable and above all to be comfortable to take risks with their own learning and to learn how to encourage students to also take risks as a basis for learning. In practical terms, where PD is concerned, this could involve teachers in PD activities that are outside their own commonly used skill sets. It may confront teachers with concepts that challenge their existing practices or understanding and is designed to stretch teachers' thinking and potentially take them beyond their current and traditional comfort zone. Teachers would be required, through supportive PD activities in workshops and micro-teaching sessions, to experiment with new methods of teaching, new approaches to classroom management, and innovative and creative ways to reach successful learning outcomes.

Approaches to PD that reflect this approach include those which invite teachers to be part of research projects, where they are fellow researchers, puzzling together with colleagues and the chief researchers to find solutions to pedagogical problems. Initially the problems may be vague and almost untouchable allowing the participants to engage in imagining, although there will be a shared understanding of where the group is heading. The participants would be seen as equal contributors to the learning of all, rather than teachers who are there to be 'developed'.

In designing effective PD activities for teachers, there needs to be freedom for participants to reach negotiated outcomes by a variety of different means using a variety of materials and approaches or strategies, and this calls for open and supportive PD sessions where taking risks is encouraged and in fact required, in order to reach identified outcomes. Risk can be built into the outcome for success. For example, "How many different teaching and learning approaches can you demonstrate and describe to assist students to use a range of genres in their writing?" A PD session which focuses upon supporting teachers to trial and create such approaches and to discuss them together as a community of learners is likely to encourage teachers to use them with learners in classrooms, especially if they have a colleague with whom they can debrief and collaborate. 
One such program in which one of the authors of this article (Mackenzie) is involved is described below as an example of PD that includes many of the elements we have outlined as required in an era of supercomplexity. The "Understanding and Supporting Young Writers Project" is operating in Victoria in 2015, whereby a university researcher and two consultants from the Victorian Curriculum and Assessment Authority have brought together 14 early childhood educators ( 7 from preschool contexts and 7 from school contexts) to puzzle over the best ways to support the young writers in their care. All participants have volunteered to work together collaboratively and to trial approaches that they suggest, within their own teaching and learning contexts and to share the outcomes with the group. Initially in this kind of situation, the participants are nervous, and feel strange and awkward when they realise that they are generating knowledge rather than just receiving knowledge. The chief researcher (Mackenzie) has successfully used this approach before with teachers in the Australian state of New South Wales. While the process is set up as research, and follows all the research ethics guidelines, one of the key outcomes is teacher professional learning. Provocations and children's authentic writing and drawing samples are used to stimulate discussions, debates and dilemmas. This is in direct contrast with didactic forms of PD that dogmatically espouse a set approach in a lock step and prescriptive manner.

As we have noted here and elsewhere (Ling \& Mackenzie, 2001), PD for teachers takes many forms. The question, however, becomes whether any of the forms of PD that are prevalent in Australia and other places currently are preparing teachers for an unknowable and supercomplex teaching context. Cole (2012) argues that because of the rapidly changing scene for teaching and learning in Australia, any "new and improved forms of professional learning are still at the "looks highly promising but not proven" stage (p.7). This suggests that in Australia currently there are some positive changes occurring in the area of PD but there is still room for further change and improvement.

Drawing on this discussion of criteria for effective PD in the current era, we now propose a form of PD which begins to address the challenges of supercomplexity and the strangeness that accompanies it for learning and for teachers. The dynamic, interactive and collaborative approach where the PD providers, the teacher participants and the workplaces are actively involved at every stage of a PD program and one where the activities are embedded within the classroom, rather than an' add on' extra, provides the framework for effective PD for an unknown future. This approach potentially leads to energy, momentum and change in all involved: the teachers; the school or early childhood setting; the system; and the professional development providers.

This interactive, collaborative and embedded approach is being taken in the "Understanding and Supporting Young Writers Project" described earlier, and demonstrates the potential for change in all elements. This change is being interactively and collaboratively facilitated by the chief researcher (the provider), the consultants from the VCAA (the system), and the educators (teacher participants) from 14 different educational settings. Potentially each member will grow in response 
to participation in the project. It is hoped that the outcome of this project (given the right support at the workplace level) will be that each teacher will initiate change within their own workplace, that the VCAA officers will initiate change via their system as a result of their participation in the project, and the chief researcher will seek to initiate change more broadly through publications and dissemination of the outcomes and findings of the project. This project is still ongoing, however, what can be reported are some of the early reactions of one participant from each of the three stakeholder groups.

As a researcher, this kind of approach to $P D$ is rewarding and stimulating for me in ways that 'stand and deliver - performance' PD isn't. It is also far more demanding. When I present to an audience, even if the topic has been determined by the group, I can monitor body language and engagement to a certain extent, but I don't get any real feedback until after the event. I don't know if I have truly connected with the participants, or if anything ever comes from the input. In projects like the one described here, I begin with a negotiated framework but then respond reflexively to the group. I am part of the group, rather than a 'sage on a stage' and the direction of the discussions is determined by the group (Participant 1 - Provider stakeholder).

Because we meet a number of times, relationships are established and the contributions of the group members change as trust is established. The analysis of student samples that participants choose to share adds to the authenticity and direction of discussions (Participant 2 - VCAA Consultant stakeholder).

This approach is collaborative and interactive and I find myself reflecting on the discussions for days after a session. These reflections then form the starting point for the next session (Participant 3 - Teacher participant stakeholder).

As is reflected in the comments of the participants quoted, the key elements that make this a different and valuable PD experience for them is that it is based on interaction between all participants, is collaborative, is co-constructed by the participants and the provider/presenter, is relevant to their work and their needs, and causes them to reflect on this after the sessions have concluded. It is not a didactic, one-way transmission of information by the provider/presenter to the participants. In the PD that the project reported here reflects, the participants work with the provider/presenter to shape the PD activities and have an active role in directing their own PD. This form of PD thus has a more pervasive effect on the participants as they carry the concepts they have addressed in the PD sessions with them into their work and reflect further on them.

The focus of the PD of the kind linked with the project described above is not predominantly or solely on skills, but instead focuses on assisting and supporting teachers as they prepare for supercomplexity by developing critical reflection, risk 
taking strategies, creativity, resilience and comfort and resourcefulness in the face of strange and awkward learning and teaching spaces in which they will find themselves and their students. To develop these dispositions through PD activities, teachers need to challenge existing beliefs and viewpoints, and to be courageous enough to resist methods of teaching that do not respect them as teachers and the students as learners.

Activities which challenge teachers to critically assess curricula and curriculum programs and documents, teaching methods, educational policies, assessment practices, and the existing teacher culture will potentially lead to a will to change and to taking informed action for change. The "Understanding and Supporting Young Writers Project" exemplifies PD that involves the development of the attributes and dispositions discussed here. While the process was still underway when this paper went to press, and final surveys, reflections and interviews had not been finalised, tentative outcomes and evidence of these are included in Table 1.

The task of PD providers then in a practical sense is to present teachers with the opportunities to reflect on their own work and that of others and also to present them with situated dilemmas that relate to their own classroom contexts and that also reflect some of the messy confusion they face when attempting to deal with these dilemmas. If teachers bring to PD sessions their own situations, confusions and dilemmas as a basis for discussion it is likely to be much more authentic and meaningful to them than some concocted activities which may or may not have any relevance to a teacher's own situation. Teachers need to be at the centre of the PD.

\section{Teachers at the Centre of PD}

When looking at effective teacher PD, Cole (2004) observed that teachers have extremely narrow views as to what constitutes PD and see it as something you always go "out to do" (p.6). Rather, Cole suggests that the term "professional development" would be better termed "professional learning" as this emphasizes teacher learning and thus puts the teacher at the centre of the action. However, sometimes in order for teachers to experience and be able to embrace this professional learning, a circuit breaker or disturbance is needed. This is necessary in order to cause the awkward spaces and unfamiliar situations that will put teachers on the spot and challenge them to disconfirm some of the practices they engage in as teachers. They need opportunities and motivation to unlearn as well as re-learn through professional learning. In terms of PD that empowers teachers and adds to their self efficacy, a number of activities have been reported in studies in Australia.

Black (1999) reports on PD activities she has provided for teachers where they have been asked to draw pictures of themselves as teachers and then to write a description of the drawing that then becomes the basis for discussion with colleagues. Black also asks teachers to use a metaphor in their drawings of themselves as teachers and she claims that this encourages self exploration of the "links between practical knowledge and practice" (p.9). Black also used story writing and journals combined with reflections as narrative pieces. 
Table 1. Preliminary findings from "Understanding and Supporting Young Writers Project"

\begin{tabular}{|c|c|}
\hline Tentative outcomes & Evidence \\
\hline $\begin{array}{l}\text { - Increased awareness of the } \\
\text { broader literacy context and } \\
\text { ways of supporting young } \\
\text { learners within that context } \\
\text { - Increased reflectiveness }\end{array}$ & $\begin{array}{l}\text { - Participants' reflective responses to readings, } \\
\text { provocations and scenarios } \\
\text { - Participants' shared analysis of writing/drawing } \\
\text { samples from both school and early childhood } \\
\text { contexts shows shifts in thinking and discourse }\end{array}$ \\
\hline $\begin{array}{l}\text { - Increased risk taking and } \\
\text { confidence on behalf of the } \\
\text { participants } \\
\text { - Increased self-efficacy in } \\
\text { regard to the teaching of } \\
\text { young writers }\end{array}$ & $\begin{array}{l}\text { - Participants' willingness to openly and } \\
\text { confidently share and to question } \\
\text { - Shared student work samples between participants } \\
\text { show a change in what is encouraged and valued }\end{array}$ \\
\hline $\begin{array}{l}\text { - Increased willingness to share } \\
\text { evidence of their work with } \\
\text { children } \\
\text { - Increased confidence in } \\
\text { analysis of children's work } \\
\text { samples } \\
\text { - Increased preparedness to } \\
\text { share the challenges and } \\
\text { possible solutions }\end{array}$ & $\begin{array}{l}\text { The number and range of samples being shared, } \\
\text { the willingness of participants to comment and } \\
\text { discuss. } \\
\text { - Anecdotal comments attached to the children's } \\
\text { work samples provided to the researchers by the } \\
\text { participants reveal deeper analysis and insight }\end{array}$ \\
\hline $\begin{array}{l}\text { The development of a shared } \\
\text { vocabulary for discussing young } \\
\text { writers and the teaching and } \\
\text { learning processes that support } \\
\text { them }\end{array}$ & $\begin{array}{l}\text { While participants were using the 'same language' } \\
\text { initially, through discussions it was obvious that their } \\
\text { understandings were sometimes different. While } \\
\text { participants from schools shared a language, and } \\
\text { participants from early childcare centres shared a } \\
\text { language, there were different understandings across } \\
\text { these groups. Time was spent 'teasing' out terms and a } \\
\text { shared glossary developed. This helped to refine } \\
\text { discussions and lead to shared meanings and shared } \\
\text { discourse. }\end{array}$ \\
\hline $\begin{array}{l}\text { Increased interest in learning } \\
\text { more }\end{array}$ & $\begin{array}{l}\text { Participants demonstrate interest in reading more } \\
\text { about the topics being shared in the focus group } \\
\text { sessions and discuss these with colleagues. }\end{array}$ \\
\hline
\end{tabular}

In other PD activities that have been undertaken by the authors of this article, teachers have been asked to brainstorm situations in which they feel empowered and then those in which they feel disempowered, and this is followed by a discussion of the specific characteristics of each of those situations. What follows is a rich discussion as to how teachers can themselves take control of the situations in which they feel disempowered and what strategies they can employ to turn them into situations of empowerment. This is especially important in PD for prospective leaders as it assists them to know how to create empowering rather than disempowering 
situations for those that they lead, including their students and their colleagues. Teachers also can realize through these kinds of experiences, that this is the kind of learning that their own students require in order to deal with a world of supercomplexity. In this way, the aim is not only engaging teachers in new learning and new ways of being-in-the-world, but their students are also engaged in these processes and, therefore, PD more directly addresses the key issue of changing outcomes in positive ways for students through PD of teachers.

\section{Conclusion}

In Australia, where it is largely the school leaders who decide how funds for PD are spent, the leadership of the school has a major impact upon what PD occurs for teachers. PD for leaders themselves is central to any change or positive outcomes for either teachers or students. This will require leaders who can overtly take risks and who will constantly challenge their own actions and what it is to be a leader in-theworld in which they function. However, whatever leaders, or teachers or those who design PD might do to bring about change and the capacity to embrace supercomplexity and the unknown, it is at the educational systemic level that massive changes are needed.

In Australia, as in many other countries currently, performativity measures such as audits, league tables of schools and universities, and standardized testing have become the norm. PD provided through departments of education and their agencies will almost inevitably focus on specific policy directions and agendas impacting on teachers' curriculum decisions, teaching approaches and learning outcomes, assessment practices or some specific program or set of prescribed materials to be used in schools. Sessions of this kind are frequently one-off half day or day-long sessions with selected staff that undertake them and then go back into their schools with the expectation that they will disseminate the ideas and strategies throughout the school. There are usually highly prescribed outcomes expected of these PD programs and the materials are frequently quite prescriptive in the way they are to be interpreted and followed by teachers and students. If teachers are to develop critical, self reflective dispositions, which allow them to be comfortable with uncertainty and competing interpretations, and which encourage them to challenge their own identities and roles, as we have advocated is necessary in the current era, PD programs of the kind usually offered through government departments and their agencies are unlikely to hit the mark. In fact quite the contrary as they are often designed to increase conformity, compliance and accountability.

There are, however, other forms of PD offered through universities or other private and independent providers that in some (though certainly not all) cases do challenge teachers to try new teaching approaches and that provide a supportive and scaffolded collegial context in which to do so. We have stressed the need for PD to allow for interactivity and dynamic relationships between all of the stakeholders involved. The "Understanding and Supporting Young Writers Project" has provided an example of PD that allows teachers to challenge their current identities, understandings, practices and beliefs. Likewise the approach utilized by Black (1999) 
and described here, where teachers use drawing, metaphor, storytelling and narrative, and reflective journals, challenges teachers to re-think their identity and role as a teacher. Cole (2012) has also concluded that PD activities that are embedded within schools as part of their everyday operations, especially where mentors are in classrooms with teachers, are amongst the most effective forms of PD. Embedded PD appears to facilitate whole-school change as distinct from PD in a one-way model where there is no transfer or sharing of knowledge resulting from the PD activity. In collaborative and collegially supportive PD sessions coupled with follow-up in schools and in subsequent sessions, teachers discuss, debate and question themselves, the curriculum, policy, assessment, teaching and learning methods, and the very essence of what it means to be a teacher in a fragile and uncertain world where the future is not knowable.

It behooves us to herald and publicize the positive outcomes and benefits of these new-era approaches to PD for teachers, so that we begin to make inroads into changing the PD culture in schools in order to make it valuable and appropriate for our current super-complex world.

\section{References}

Australian Institute for teaching and School Leadership (2011). A background paper to inform the development of a national professional development framework for teachers and school leaders. Dr Helen Timperley. AITSL.

Barnett, R. (2000). University knowledge in an age of supercomplexity. Higher Education 40, 409-422.

Barnett, R. (2011). Realizing the University in an Age of Supercomplexity. Ballmoor Bucks: The Society for research into Higher Education and OUP.

Barnett, R. (2012). Learning for an unknown future, Higher Education Research \& Development, 31(1), 65-77.

Barnett, R. (2015). Thinking and Rethinking the University in The Selected Works of Ronald Barnett (e-book). Routledge Oxon and NY.

Black, A. L. (1999). Empowering Teachers: Using teaching Images to Understand Self. Creche and Kindergarten Annual Early Childhood Conference, Brisbane, Australia (unpublished).

Cole, P. (2004). Professional development: A great way to avoid change IARTV. Melbourne, Seminar Series No 140.

Cole, P. (2012). Linking effective professional learning with effective teaching practice. AITSL.

Ingvarson, L., Meiers, M., \& Beavis, A. (2005). Factors affecting the impact of professional development programs on teachers' knowledge, practice, student outcomes and efficacy. Education Policy Analysis Archives, 13(10), 1-28.

Lauer, P. A., Christopher, D. E., Firpo-Triplett, R., \& Buchting, F. (2014). The impact of short-term professional development on participant outcomes: a review of the literature, Professional Development in Education, 40(2), 207-227.

Ling, L. M., \& Mackenzie, N. (2001). The professional development of teachers in Australia. European Journal of Teacher Education, 24(2), 87-89. 
Mackenzie, N. (1997). Professional Development: A Qualitative Case Study. Unpublished Masters thesis, La Trobe University, Albury-Wodonga Campus, Graduate School of Education.

Opfer, V., \& Pedder, D. (2011). Conceptualizing teacher professional learning. Review of Educational Research, 81(3), 376-407.

Possner, D. (2002). Education for the $21^{\text {st }}$ century, Phi Delta Kappan, 84(4), 316-317.

Taylor, M., Yates, A., Meyer, L. H., \& Kinsella, P. (2011). Teacher professional leadership in support of teacher professional development. Teaching and Teacher Education, 27(1), 85-94. http://dx.doi.org/10.1016/j.tate.2010.07.005 (accessed 22/3/2015).

Victorian Institute of Teaching, http://www.vit.edu.au/registration/i-want-to-renew-myregistration/pages/keeping-records-of-professional-development.aspx

Victorian Institute of Teaching, http://www.vit.edu.au/registration/i-want-to-renew-myregistration/registration-process-faqs/pages/default.aspx (accessed 23/5/2015).

Weldon, P., Rowley, G., \& McKenzie, P. (2011). Profiles of teachers in selected Curriculum Areas: Further Analyses of the Staff in Australia's Schools 2010 Survey, Canberra, Department of Education Employment and Workplace Relations. 